\title{
The effect of acute hyperglycaemia on QTc duration in healthy man
}

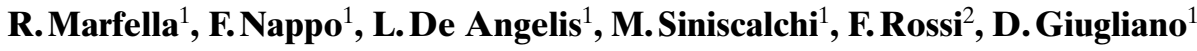 \\ ${ }^{1}$ Department of Geriatrics and Metabolic Diseases, Second University of Naples, Italy \\ ${ }^{2}$ Institute of Pharmacology and Toxicology, Second University of Naples, Italy
}

\section{Abstract}

Aims/hypothesis. Prolongation of heart rate-adjusted QT (QTc) is associated with an increased risk of coronary heart disease and sudden death. The objective of this study was to investigate whether acute increases of plasma glucose concentrations in healthy subjects could influence QTc and QTc dispersion.

Methods. Plasma glucose concentrations were quickly raised to $15 \mathrm{mmol} / \mathrm{l}$ in 20 healthy subjects $(10 \mathrm{men} /$ 10 women) and maintained for $2 \mathrm{~h}$. On another occasion, and in random order, all subjects underwent the same hyperglycaemic clamp as above and an infusion of the somatostatin analogue octreotide $(25 \mu \mathrm{g}$ as iv bolus followed by a $0.5 \mathrm{~g} / \mathrm{min}$ infusion) to block the release of endogenous insulin.

Results. Systolic and diastolic blood pressures, heart rate and plasma catecholamine concentrations showed significant increases $(p<0.05)$ starting after $60 \mathrm{~min}$ of hyperglycaemia. QTc, QTc dispersion and PR interval also showed significant increments at $120 \mathrm{~min}$ of the hyperglycaemic clamp. The infusion of octreotide did not influence QTc duration, QTc dispersion, PR interval and the haemodynamic effects of acute hyperglycaemia.

Conclusion/interpretation. The results show that acute hyperglycaemia produces significant increments of QTc and QTc dispersion in normal subjects. In this context, endogenously released insulin during acute hyperglycaemia seems to play a minor part. [Diabetologia (2000) 43: 571-575]

Keywords Acute hyperglycaemia, healthy subjects, QTc duration, QTc dispersion, hyperinsulinaemia, octreotide.
A prolonged heart rate-adjusted QT (corrected QT interval: QTc) is a risk factor for sudden death in patients with the long QT syndrome [1], patients with myocardial infarction [2], subjects referred for Holter monitoring [3] and healthy men and women [4-5]. A prolonged QTc interval has been reported in diabetic patients with autonomic neuropathy [6] and is associated with an increased mortality risk in nephropathic Type I (insulin-dependent) diabetic patients [7], as well as with fasting and post-challenge glucose concentrations in elderly people [8]. Moreover, an associ-

Received: 12 October 1999 and in revised form: 24 January 2000

Corresponding author: R. Marfella MD, PhD, Via Emilio Scaglione, 141, I-80145 Naples, Italy ation of post-load insulin concentrations with QTc dispersion has been reported in a series of healthy subjects during oral glucose testing [9].

A recent epidemiologic study in Type II (non-insulin-dependent) diabetic patients shows that the prevalence of QTc prolongation is as high as $26 \%$ and is associated with heart disease [10].

The aims of our study were to evaluate the effect of acute hyperglycaemia on haemodynamic variables, as well as QTc duration and QTc dispersion in normal subjects, and to dissect the effects of hyperglycaemia from those of hyperinsulinaemia by blocking the release of endogenous insulin with octreotide, a somatostatin analogue. 
Table 1. Characteristics of study patients

\begin{tabular}{lc}
\hline Age $($ years $)$ & $44 \pm 6$ \\
Sex $(\mathrm{M} / \mathrm{F})$ & $10 / 10$ \\
BMI $\left(\mathrm{kg} / \mathrm{m}^{2}\right)$ & $25 \pm 1.1$ \\
Plasma glucose $(\mathrm{mmol} / \mathrm{l})$ & $5.4 \pm 1.0$ \\
Plasma cholesterol $(\mathrm{mmol} / \mathrm{l})$ & $4.6 \pm 0.9$ \\
Plasma triglyceride $(\mathrm{mmol} / \mathrm{l})$ & $1.7 \pm 0.9$ \\
Systolic blood pressure $(\mathrm{mm} \mathrm{Hg})$ & $114 \pm 9.3$ \\
Diastolic blood pressure $(\mathrm{mm} \mathrm{Hg})$ & $72 \pm 7$ \\
Heart rate (beat/min) & $70 \pm 6$ \\
QTc $(\mathrm{ms})$ & $413 \pm 26$ \\
QTc dispersion $(\mathrm{ms})$ & $32 \pm 9$ \\
PR (ms) & $168 \pm 20$ \\
\hline
\end{tabular}

Values are given as mean \pm SD

\section{Subjects and methods}

We studied 20 healthy volunteers (Table 1) recruited from the medical and paramedical staff of the Department of Geriatrics and Metabolic Diseases, Second University of Naples, Italy. All had normal blood pressure, did not have diabetes, and had no history of hyperlipidaemia or family history of premature vascular disease. The protocol of the study was approved by the ethics committee of our institution; informed consent to participate in this study was obtained from all subjects.

Study protocol. After a 12-h overnight fast subjects arrived at the metabolic ward between 0800 and 0830 and were placed in a supine comfortable position with the room temperature kept between 20 and $24^{\circ} \mathrm{C}$. All subjects had been instructed to refrain from coffee and smoking on the morning of the test day. Intravenous lines were inserted in a large antecubital vein of one arm for infusion and in a dorsal vein of the controlateral arm for blood sampling. Patency was preserved by a slow saline infusion $(0.9 \% \mathrm{NaCl})$. The subjects were then prepared for automatic measurements of blood pressure and heart rate. The study began after the subjects had rested for 30 min or longer and after three consecutive measurements of blood pressure, heart rate and ECG, variables differing less than $5 \%$ were recorded. All subjects underwent the following tests in random order and separated by at least a 3 day interval:

(1) Hyperglycaemic glucose clamp (Control Study) in which plasma glucose concentrations were quickly raised with a bolus injection of $0.33 \mathrm{~g} / \mathrm{kg}$ glucose (50\% solution) followed by a variable $30 \%$ glucose infusion to achieve steady state plasma glucose concentrations of about $15 \mathrm{mmol} / \mathrm{l}$ for $120 \mathrm{~min}$. To prevent hypokalaemia, $0.26 \mathrm{mmol} / \mathrm{K} \mathrm{KCl}$ was added to the glucose solution. The test was done with the aid of an artificial pancreas (Biostator, Life Science, Miles, Elkart, Ind., USA).

(2) Another test consisted of a hyperglycaemic clamp as described above and an octreotide infusion (Octreotide study) (Longastatina, Italfarmaco, Milan, Italy, $25 \mu \mathrm{g}$ as iv bolus followed by a $0.5 \mu \mathrm{g} / \mathrm{min}$ infusion). The infusion of octreotide started $5 \mathrm{~min}$ before the clamp and was discontinued at the end of the experiments, $120 \mathrm{~min}$ later.

To ascertain whether QT changes could have been influenced by other confounding variables, control experiments were carried out in six normal subjects in whom we infused an identical volume of saline (about $300 \mathrm{ml}$ ) over $2 \mathrm{~h}$.
Procedures. Heart rate and finger arterial pressure were recorded with a non invasive technique (Ohmeda 2300, Finapres, Englewood, Calif., USA) that uses the unloaded artery principle [11]. Data were elaborated by a software that allowed systolic blood pressure (SBP), diastolic blood pressure (DBP) and heart rate (HR) to be expressed in graphs. R-R, Q-T and $\mathrm{P}-\mathrm{R}$ intervals were recorded with a standard resting 12-lead ECG at $50 \mathrm{~mm} / \mathrm{s}$. All electrocardiograms were measured by a cardiologist who was blinded from other information. The QT interval was taken from the onset of the QRS to the end of the $\mathrm{T}$ wave. If $\mathrm{U}$ waves were present, QT interval was measured to the nadir of the curve between $T$ and $U$ waves. QT intervals were corrected with Bazett's formula $(\mathrm{QTc}=\mathrm{QT} / \sqrt{ } \mathrm{R}$ $\mathrm{R})$; QTc dispersion was calculated as interlead variability of QTc interval (QTc-dispersion $=$ QTc $\max -$ QTc min). Samples for plasma glucose were collected in tubes containing a trace of sodium fluoride and those for insulin in tubes containing a mixture $(0.1 \mathrm{ml} / \mathrm{ml}$ blood $)$ of EDTA-Trasylol solution $(5000 \mathrm{U} / \mathrm{ml}$ Trasylol; Bayer, Leverkusen, Germany; $1.2 \mathrm{~g} / \mathrm{l}$ disodium EDTA). Plasma glucose was determined with the glucose oxidase method on an autoanalyser (Beckman, Fullerton, Calif., USA). Plasma insulin concentrations were determined by RIA. Plasma catecholamines were measured at 0 and 120 min of the studies. Samples were collected in iced heparinised tubes, and the plasma was separated within $120 \mathrm{~min}$ and stored at $-70^{\circ} \mathrm{C}$ as perchloric acid extracts until assayed. Plasma catecholamines were measured with high performance liquid chromatography. In our laboratory, the assay has a detection limit of $20 \mathrm{ng} / \mathrm{l}$; the intra-assay and inter-assay coefficients of variation are 8.0 and $8.6 \%$, respectively.

Statistical analysis. Results are given as mean \pm SD. To detect differences in response to hyperglycaemia or hyperglycaemia plus octreotide, a two-way analysis of variance (ANOVA) for repeated measures was done followed by a pair wise multiplecomparison procedure (Student-Newman-Keuls test) to locate the significant difference indicated by ANOVA. A $p$ value less than 0.05 was considered significant.

\section{Results}

Hyperglycaemic clamp. Plasma glucose stabilised at $15 \mathrm{mmol} / \mathrm{l}$ during the clamp; plasma insulin showed a biphasic pattern with an early rise at $10 \mathrm{~min}$ followed by a gradual and sustained increase (Fig.1). Systolic blood pressure, DBP and HR increased during the clamp and remained significantly above baseline (Table 2). Plasma norepinephrine rose from a basal concentration of $182 \pm 48$ to $249 \pm 45(p<0.05)$ and $254 \pm 50 \mathrm{ng} / \mathrm{l}(p<0.02)$ after 60 and $120 \mathrm{~min}$ of the clamp, respectively; plasma epinephrine rose from a basal concentration of $55 \pm 16$ to $72 \pm 22(p=\mathrm{NS})$ and $88 \pm 27 \mathrm{ng} / \mathrm{l}$ at $120 \mathrm{~min}$ of the clamp $(p<0.02)$. QTc and QTc dispersion were significantly higher after the clamp: QTc increased from a basal $413 \pm 26$ to $442 \pm 29 \mathrm{~ms}(p<0.05)$ at the end of the clamp and QTc dispersion increased from $32 \pm 9$ to $55 \pm 12 \mathrm{~ms}$ $(p<0.01)$ (Fig. 2, Table 3). There was no difference in QTc response to hyperglycaemia between men and women. The PR interval showed a significant increment at $120 \mathrm{~min}$ of the clamp (from $168 \pm 20$ to $181 \pm 28 \mathrm{~ms}, p<0.05)$ (Fig. 2). 

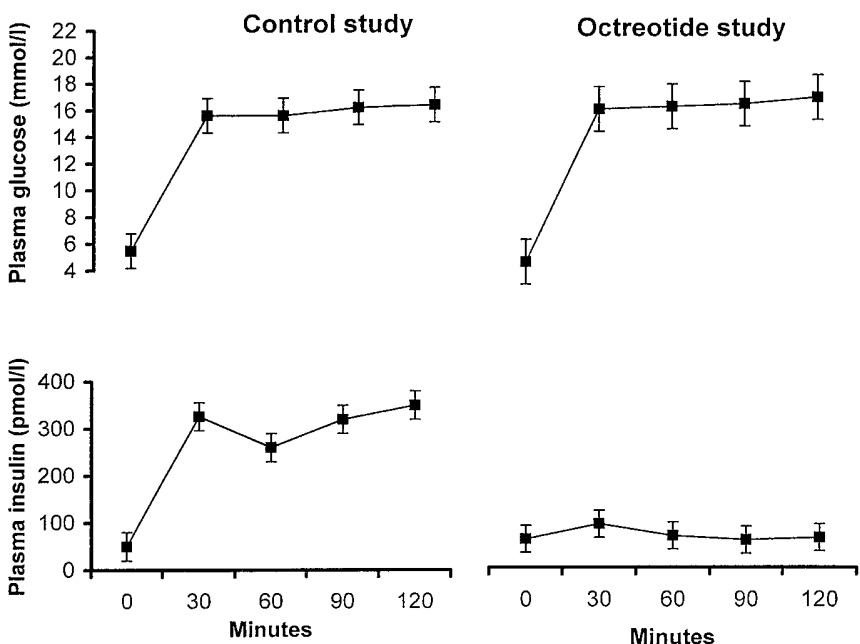

Fig. 1. Plasma glucose and insulin concentrations during the two different hyperglycaemic clamps in 20 healthy subjects

Hyperglycaemic clamp plus octreotide. Basal and clamped plasma glucose concentrations in the octreotide study were not significantly different from those of the control study; glucose-stimulated insulin responses were noticeably reduced by octreotide (Fig.1). Haemodynamic and ECG variables rose considerably in the octreotide study; these changes did not differ from those recorded in the control study (Fig. 2, Table 2). Plasma catecholamine concentrations did not differ between the two studies. Infusion of octreotide alone in four normal subjects produced small changes of haemodynamic and ECG variables. Similarly, no important changes were observed in any of the variables investigated during saline infusion (data not shown).

\section{Discussion}

Short-term hyperglycaemia in normal subjects causes considerable increases of systolic and diastolic blood pressure and heart rate $[12,13]$. The novel finding of this study is that acute hyperglycaemia produces sig-
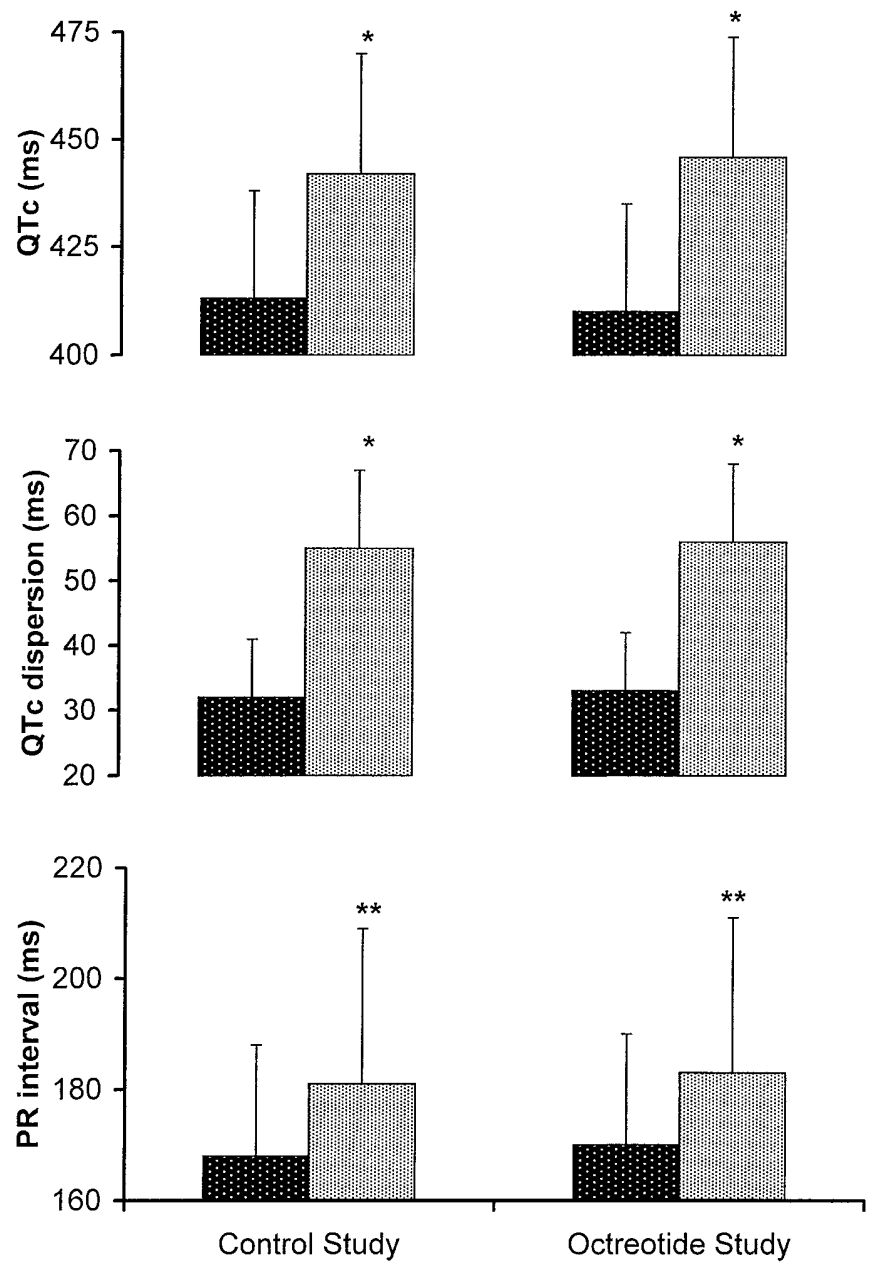

Fig. 2. Qtc intervals, QTc dispersion and PR intervals during hyperglycaemic clamps (Control study, left bar basal values, right bar 120 min values) and hyperglycaemic clamps plus octreotide (Octreotide study, left bar basal values, right bar 120 min values). $* p<0.05$. ** $p<0.01$ vs basal values

nificant increments of QTc and QTc dispersion, as well as PR interval, in healthy people.

The length of the QT interval, which is easily obtained from standard resting electrocardiogram, represents the time interval between the start of activa-

Table 2. Haemodynamic variables during hyperglycaemic clamps (Control study) and hyperglycaemic clamps plus octreotide (Octreotide study)

\begin{tabular}{|c|c|c|c|c|}
\hline & \multicolumn{2}{|c|}{ Control study } & \multicolumn{2}{|c|}{ Octreotide study } \\
\hline & 0 & $120 \mathrm{~min}$ & 0 & $120 \mathrm{~min}$ \\
\hline Systolic blood pressure (mm Hg) & $114 \pm 9.3$ & $122 \pm 12^{\mathrm{a}}$ & $115 \pm 8.9$ & $123 \pm 11^{\mathrm{a}}$ \\
\hline Heart rate (beat $/ \mathrm{min})$ & $70 \pm 6$ & $77 \pm 4^{\mathrm{a}}$ & $71 \pm 5$ & $77.5 \pm 6^{\mathrm{a}}$ \\
\hline Plasma epinephrine (ng/l) & $55 \pm 16$ & $88 \pm 27^{b}$ & $48 \pm 12$ & $85 \pm 22^{b}$ \\
\hline Plasma norepinephrine (ng/l) & $182 \pm 42$ & $254 \pm 50^{b}$ & $175 \pm 39$ & $251 \pm 43^{b}$ \\
\hline Serum potassium $(\mathrm{mmol} / \mathrm{l})$ & $4.1 \pm 0.7$ & $3.9 \pm 0.6$ & $4.3 \pm 0.8$ & $4.5 \pm 0.4$ \\
\hline $\mathrm{pH}$ & $7.38 \pm 0.4$ & $7.38 \pm 0.3$ & $7.39 \pm 0.3$ & $7.39 \pm 0.3$ \\
\hline
\end{tabular}

Data are mean \pm SD. ${ }^{\mathrm{a}} p<0.001$ vs basal values; ${ }^{\mathrm{b}} p<0.05$ 
Table 3. Hyperglycaemic clamp

\begin{tabular}{|c|c|c|c|c|}
\hline & QTs (ms) & & QTc disper & ion (ms) \\
\hline & 0 & $120 \mathrm{~min}$ & 0 & $120 \mathrm{~min}$ \\
\hline & 435 & 470 & 22 & 50 \\
\hline & 385 & 405 & 37 & 65 \\
\hline & 390 & 407 & 21 & 60 \\
\hline & 380 & 411 & 39 & 64 \\
\hline & 425 & 461 & 24 & 33 \\
\hline & 419 & 470 & 26 & 61 \\
\hline & 376 & 407 & 38 & 68 \\
\hline & 436 & 459 & 43 & 63 \\
\hline & 435 & 461 & 42 & 60 \\
\hline & 378 & 398 & 25 & 41 \\
\hline & 428 & 453 & 24 & 40 \\
\hline & 389 & 401 & 25 & 35 \\
\hline & 424 & 462 & 26 & 66 \\
\hline & 433 & 469 & 46 & 64 \\
\hline & 380 & 404 & 25 & 66 \\
\hline & 428 & 469 & 23 & 45 \\
\hline & 433 & 462 & 40 & 59 \\
\hline & 418 & 471 & 39 & 44 \\
\hline & 415 & 450 & 38 & 67 \\
\hline & 430 & 459 & 43 & 45 \\
\hline Mean & 412.6 & 442.45 & 32.3 & 54.8 \\
\hline DS & 26.18078 & 29.00903 & 8.718402 & 11.7724 \\
\hline
\end{tabular}

tion of the ventricle and completion of its repolarisation. QT interval is influenced by the autonomic tone [14] and represents an index of myocardial refractoriness and electrical stability; these are critical determinants of ventricular fibrillation and sudden death [15]. An association between a prolonged QT interval and sudden cardiac death has been found in various diseases including coronary artery disease and heart failure [16-17]. In diabetic patients, QT interval lengthening has been linked to an increased risk for unexpected death [18-19].

Two mechanisms have been formulated to explain the increased cardiovascular risk in the presence of QTc prolongation. Firstly, dispersion of repolarisation as a consequence of predominance of left sympathetic nerve activity is held responsible for high risk of ventricular fibrillation [20]. Secondly, a disturbed myocardial membrane function is believed to lead to electrical instability [21]. Whatever the underlying mechanism, sympathetic stimulation unopposed by vagal activity possibly induces ventricular electrical instability, resulting in a high risk of arrhythmia and sudden death [22]. The results of our study confirm previous findings [12] that acute hyperglycaemia produces an increase of sympathetic activity as evident by increased plasma catecholamine concentrations.

Recent reports suggest that hyperinsulinaemia, insulin resistance or both may have some role in increasing QTc interval and QTc dispersion [8]. To dissect the respective role of hyperglycaemia and hyperinsulinaemia on QTc duration, we repeated the hyperglycaemic clamp studies with the somatostatin analogue octreotide, which inhibits glucose-induced in-

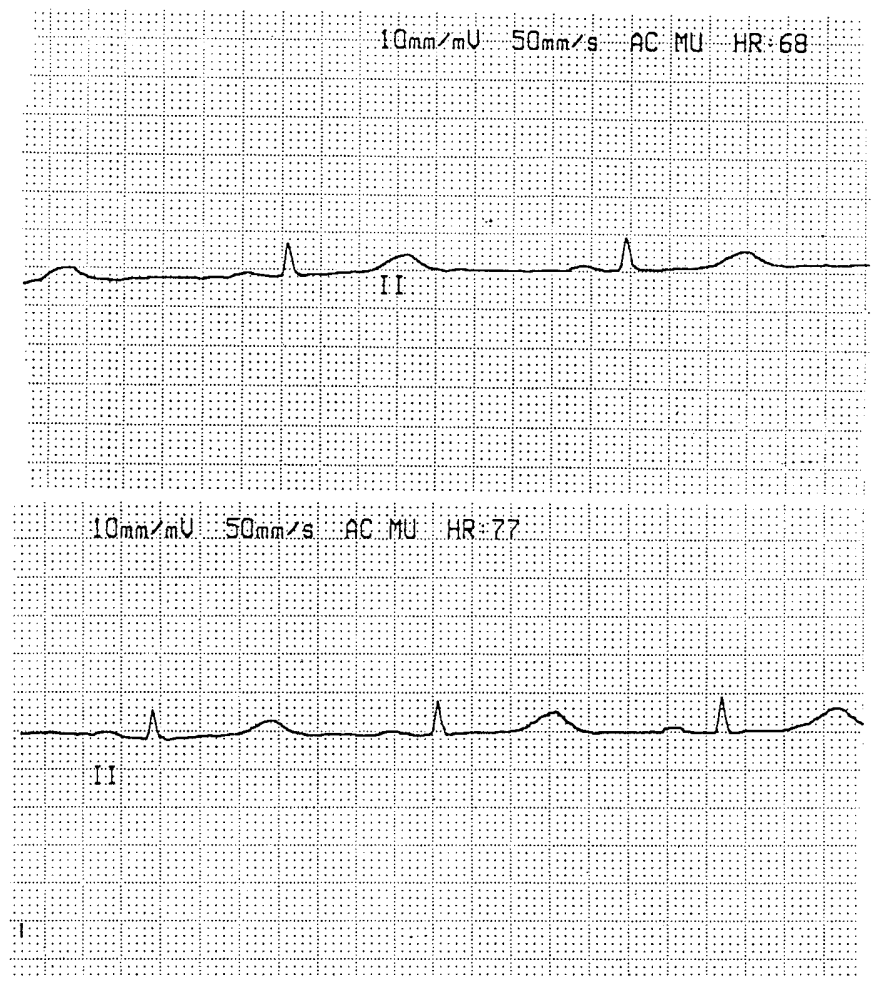

Fig.3. ECG example at basal and 120 min after the hyperglycaemic clamp. Upper panel: basal ECG (heart rate 68 beats/ min, QT $400 \mathrm{~ms}$, QTc $435 \mathrm{~ms}$ ), lower panel: ECG after $120 \mathrm{~min}$ (heart rate 77 beats/min, QT $400 \mathrm{~ms}$, QTc $470 \mathrm{~ms}$ )

sulin release. The haemodynamic and ECG changes induced by acute hyperglycaemia persisted during octreotide infusion, suggesting that insulin plays a minor part in these changes. Pertinent to the present findings are the results of a recent study [8] showing that QTc duration was significantly associated with glucose concentrations 60 and 120 min after an oral glucose load in elderly men with normal and impaired glucose tolerance, as well as in newly diagnosed diabetic patients.

Hyperglycaemia could be responsible for QTc prolongation by increasing the cytosolic calcium content, as has been reported to occur in healthy subjects during oral glucose testing [23]. Reduction of $\mathrm{Na}^{+} \mathrm{K}^{+}$ATPase activity through depressed NO formation [24], inhibition of $\mathrm{Ca}^{2+}$-ATPase [25] and activation of $\mathrm{Na}^{+} / \mathrm{H}^{+}$antiport [26] are possible molecular mechanisms. In theory, reduced NO availability in vivo, as evidenced during acute hyperglycaemia in humans [13], possibly leads to increased intracellular calcium content.

Acute hyperglycaemia also induced statistically significant increments of PR interval. The PR interval on the surface ECG serves as an index of atrioventricular conduction $[27,28]$. To the best of our knowledge, we are not aware of any study describing an association of diabetes or hyperglycaemia with the PR interval. At present, we have no plausible ex- 
planations for this effect although one might speculate that the same mechanisms contributing to the effect of acute hyperglycaemia on QTc dispersion is possibly also operative.

In conclusion, we have shown that acute hyperglycaemia produces a statistically significant increase of QTc interval and QTc dispersion in normal subjects. The relevance of these short-term changes to the high mortality rates of the diabetic patient is speculative. The prolongation of the QT interval in diabetic patients may also be due to reasons other than hyperglycaemia (coronary heart disease, heart failure, drugs etc.). Our results possibly point to a new mechanism by which hyperglycaemia increases cardiovascular risk in diabetes mellitus.

\section{References}

1. Jervell A, Lange-Nielsen F (1957) Congenital deaf mutism: functional heart disease with prolongation of the QT interval, and sudden death. Am Heart J 54: 59-68

2. Peters RW, Byington RP, Barker A, Yusuf S (1990) BHAT Study Group. Prognostic value of prolonged ventricular repolarization following myocardial infarction: the BHAT experience. J Clin Epidemiol 43: 167-172

3. Algra A, Tijssen JGP, Roelandt JRTC, Pool J, Lubsen J (1991) QTc prolongation measured by standard 12-lead electrocardiography is an independent risk factor for sudden death due to cardiac arrest. Circulation 83: 1888-1894

4. Schouten EG, Dekker JM, Meppelink P, Kok FJ, Vandeubroucke JP, Pool J (1991) QT-interval prolongation predicts cardiovascular mortality in an apparently healthy population. Circulation 84: 1516-1523

5. Dekker JM, Schouten EG, Kromhout D, Pool J (1994) QTc prolongation predicts coronary heart disease in middleaged and elderly men: the Zutphen Study. Circulation 90: 779-785

6. Oka H, Mochio S, Sato K, Sato H, Katayama K (1996) Prolongation of QTc interval and autonomic nervous dysfunction in diabetic patients. Diabetes Res Clin Pract 31: 63-70

7. Sawicki PT, Dahne R, Bender R, Berger M (1996) Prolonged QT interval as a predictor of mortality in diabetic nephropathy. Diabetologia 39: 77-81

8. Dekker JM, Feskens EJM, Schouten EG, Klootwijk P, Pool J, Kromhout D (1996) The Zutphen Elderly Study: QTc duration is associated with levels of insulin and glucose tolerance. Diabetes 45: 376-380

9. Watanabe T, Ashikaga T, Nishizaki M, Yamawake N, Arita M (1997) Association of insulin with QTc dispersion. Lancet 350: 1821-1822

10. Borra M, Veglio M, Bruno G et al. (1999). Prevalence of QTc prolongation in Type II diabetic: an Italian population-based cohort. Diabetologia 42[Suppl 1]:A295 (Abstract)

11. Parati G, Casadei R, Groppelli A, Di Rienzo M, Mancia G (1989) Comparison of finger and intra-arterial blood pressure monitoring at rest during laboratory testing. Hypertension 13: 647-655

12. Marfella R, Verrazzo G, Acampora R et al. (1995) Glutathione reverses systemic hemodynamic changes induced by hyperglycemia in healthy subjects. Am J Physiol 268:E1167-E1173

13. Giugliano D, Marfella R, Coppola L et al. (1997) Vascular effects of acute hyperglycemia in humans are reversed by L-Arginine. Evidence for reduced availability of nitric oxide during hyperglycemia. Circulation 95: 1783-1790

14. Ahnve S, Vallin H (1982) Influence of heart rate and inhibition of autonomic tone on the QT interval. Circulation 65: 435-439

15. Vlay SC, Mallis GI, Brown EJ Cohn PF (1984) Documented sudden cardiac death in prolonged Q-T syndrome. Arch Intern Med 144: 833-834

16. Barr CS, Nans A, Freeman M, Lang C, Struthers AD (1994) QT dispersion and sudden unexpected death in chronic heart failure. Lancet 343: 327-329

17. Bellavere F, Ferri M, Guarini G (1988) Prolonged QT period in diabetic autonomic neuropathy: a possible role in sudden cardiac death. Br Heart J 59: 379-383

18. Ewing DJ, Boland O, Neilson JMM, Cho CG, Clarke BF (1991) Autonomic neuropathy, QT interval lengthening, and unexpected deaths in male diabetic patients. Diabetologia 34: 182-185

19. Jermendy C, Tòth L, Voros P, Koltai MZ, Pogatsa G (1991) Cardiac autonomic neuropathy and QT interval length. A follow-up study in diabetic patients. Acta Cardiol 46: 189-200

20. Ben-David J, Zipes DP (1988) Differential response to right and left ansae subclaviae stimulation of early after depolarizations and ventricular tachycardia induced by cesium in dogs. Circulation 78: 1241-1250

21. Schwartz PJ, Priori SG (1990) Sympathetic nervous system and cardiac arrhythmias. In: Zipes DP, Jalife J (eds) Cardiac Electrophysiology: From Cell to Bedside. Saunders, Philadelphia pp 330-343

22. Zipes DP (1992) The long QT syndrome: a Rosetta stone for sympathetic related ventricular tachyarrhythmias. Circulation 84: 1414-1419

23. Resnick LA, Barbagallo H, Gupta RK, Laragh JE (1993) Ionic basis of hypertension in diabetes mellitus. Role of hyperglycemia. Am J Hypertens 6: 413-417

24. Gupta S, Sussman I, Mc Artliur CS, Tornheim K, Cohen RA, Ruderman NB (1992) Endothelium-dependent inhibition of $\mathrm{Na}+-\mathrm{K}+$ ATPase activity in rabbit aorta by hyperglycemia. Possible role of endothelium-derived nitric oxide. J Clin Invest 90: 727-732

25. Davis FB, Davis PJ, Gerard N et al. (1985) The effect of in vivo glucose administration on human erythrocyte $\mathrm{Ca}^{2}+$ ATPase activity and on enzyme responsiveness in vitro to thyroid hormone and calmodulin. Diabetes 34 : 639-646

26. Williams B, Howard KL (1994) Glucose-induced changes in $\mathrm{Na}+/ \mathrm{H}+$ antiport activity and gene expression in cultured vascular smooth muscle cells. Role of protein kinase C. J Clin Invest 93: 2623-2631

27. Gibbons WR, Zygmunt AC (1992) Excitation-contraction coupling in heart: The Heart and Cardiovascular System, 2nd edn. Raven Press, New York, pp 1249-1279

28. Fleg JL, Das DN, Wright J, Lakatta EG (1990)Age-associated changes in the components of atrioventricular conduction in apparently healthy volunteers. J Gerontol 45: M95-M100 